\title{
A INTERDISCIPLINARIDADE NO ESTÁGIO SUPERVISIONADO: (IN) CONGRUENCIAS NA PRÁTICA ESCOLAR
}

\author{
INTERDISCIPLINARITY IN SUPERVISED INTERNSHIP: \\ (IN)CONGRUENCIES IN SCHOOL PRACTICE
}

\section{LA INTERDISCIPLINARIDAD EN LA PRÁCTICA SUPERVISADA: (IN) CONGRUENCIAS EN LA FORMACIÓN ESCOLAR}

\author{
Andrea Abreu Astigarraga ${ }^{1}$ \\ RAILANE Bento Vieira SABÓIA ${ }^{\mathrm{II}}$ \\ 'Universidade Estadual Vale do Acaraú (UVA), Sobral/CE - Brasil \\ "Universidade Estadual do Ceará (UECE), Fortaleza/CE, Brasil
}

\begin{abstract}
RESUMo O objetivo desta pesquisa foi identificar e analisar as (in) congruências encontradas na práxis interdisciplinar no Estágio Supervisionado em Educação Infantil. O contexto da pesquisa foi o Curso de Pedagogia da UVA, Ceará, e nas escolas públicas de um município cuja proposta pedagógica enfatiza avaliação externa no Infantil V e os eixos de Linguagens e Códigos. Pesquisa de abordagem qualitativa. Devido à ausência de documentação escrita e/ou virtual sobre currículo recentemente formulada, recorremos à entrevista com a coordenadora da Educação Infantil no supracitado local de pesquisa. Além deste instrumento metodológico, incluímos aplicação de questionário com 43 acadêmicas do sétimo e do oitavo períodos. Os resultados apontam como incongruências: a dificuldade inicial na aceitação dos estagiários pelos gestores e professores; a aplicação das provas externas no mesmo período do estágio nas turmas do Infantil V; a exigência de mudança na estrutura e nos temas dos projetos para adequação aos eixos de Linguagens e Códigos, entre outros. Por outro lado, reconhecemos como congruências: a criação de um espaço de diálogo com as professoras e gestoras escolares; aceitação e fortalecimento das práticas lúdicas; a superação da fragmentação de conhecimentos, de forma a contribuir significativamente na formação das (os) pedagogas (os), aliando teoria e prática.
\end{abstract}

Palavras-chave: Interdisciplinaridade; Estágio Supervisionado; Educação Infantil; Projeto Pedagógico. 
AbSTRaCr The aim of this study was to identify and analyze the (in)congruencies in the interdisciplinary practice of supervised internship in early preschool education. The research was conducted in course of Pedagogy of the Universidade Estadual Vale do Acaraú, Sobral - Ceará, and public schools in a city whose pedagogical proposal focuses on external exams in the areas of language and arts for preschoolers. This is qualitative research. Due to the absence of written and/or virtual documentation and the recent curriculum reformulation, we interviewed the preschool coordinator from one of the municipalities. In addition to the interview, we administered a questionnaire to 43 students in the seventh and eighth grades. Therefore, the results pointed out the following incongruencies: resistance from administrative staff and teachers to accept interns, administration of external exams within the same period of internship in preschool classes, demand for changes in the structure and themes of the projects to adapt to the areas of language and arts, among others. As for the congruencies, we found the following: openness to dialogue with teachers and school administrators, acceptance and strengthening of playful practices, overcoming knowledge fragmentation that significantly contributes to the training of interns as it combines theory and practice.

KEYWORDS: INTERDISCIPLINARITY; SUPERVISED INTERNSHIP; CHILDHOOD EDUCATION; PEDAGOGICAL PROJECT.

Resumen El objetivo de esta pesquisa fue identificar y analizar las (in) congruencias encontradas en la formación interdisciplinar de la Práctica Supervisada en la Educación Infantil. El contexto de la pesquisa fue el Curso de Pedagogía de la UVA, Ceará, en las escuelas públicas de un municipio cuya propuesta pedagógica enfatiza la evaluación externa en el quinto año de Educación Infantil y los ejes de los Lenguajes y Códigos. Debido a la ausencia de documentación escrita y virtual sobre currículo recientemente formulada, recurrimos a la entrevista con la coordinadora de Educación Infantil en el lugar de la pesquisa, anteriormente citado. Además de este instrumento metodológico, incluimos la aplicación de un cuestionario con 43 alumnos del séptimo y octavo año. Los resultados señalan como incongruencias: la dificultad inicial para la aceptación de los(as) aprendices por parte de los administradores y profesores, la aplicación de las pruebas externas en el mismo período de la práctica supervisada en el quinto año infantil, la exigencia de cambio en la estructura e temas de los proyectos para su adecuación a los ejes de los Lenguajes y Códigos, entre otros. Por otro lado, reconocemos como congruencias: la creación de un espacio de diálogo con las profesoras y administradoras escolares, la aceptación y fortalecimiento de las prácticas lúdicas, la superación de la fragmentación de conocimientos, de modo a contribuir significativamente en la formación de las(os) pedagogas(os), aliando teoría y práctica.

Palabras-clanes: Interdisciplinaridad. Práctica SuPERVISAda. Educación InFANTIL. Proyecto Pedagógico.

\section{INTRODUÇão}

A Educação Infantil deve ter propostas pedagógicas que respeitem três princípios: o ético - referente à autonomia, às singularidades e à identidade; o político - referente aos direitos de cidadania; e o estético - referente à sensibilidade, à criatividade, à ludicidade e à 
liberdade de expressão, nas diferentes manifestações artísticas e culturais (BRASIL, 2010).

De acordo com Referencial Curricular Nacional da Educação Infantil (RCNEI), durante essa fase educacional, "[...] é direito das crianças brincar como forma particular de expressão, pensamento, interação e comunicação infantil” (BRASIL, 1998, p.13). Acrescenta-se ainda, que é necessário oportunizar às crianças "[...] condições para as aprendizagens que ocorrem nas brincadeiras e aquelas advindas de situações pedagógicas intencionais ou aprendizagens orientadas pelos adultos" (BRASIL, 1998, p. 23), e que estas atividades, ofertadas com diferentes objetivos, ocorram concomitantemente ao processo de desenvolvimento infantil.

As Diretrizes Curriculares Nacionais para a Educação Infantil (DCNEI) determinam, desde 2009, que as instituições que atuam nessa etapa de ensino criem procedimentos para a avaliação do desenvolvimento das crianças. Todavia, esse processo não deve ter como objetivo a seleção, a promoção ou a classificação dos pequenos. Para isso, precisa considerar "a observação crítica e criativa das atividades, das brincadeiras e interações das crianças no cotidiano" (BRASIL, 2009, p.04), empregando múltiplos registros, o que pode gerar dúvidas e interpretações equivocadas.

Não obstante a isso, é possível encontrar casos de aplicação de provas em turmas do Infantil III (com crianças de 03 anos), conforme relatou Rita Coelho, coordenadora-geral de Educação Infantil do Ministério da Educação (MEC), no $1^{\circ}$ Seminário Nacional de Avaliação da Educação Infantil, realizado em São Paulo, em 2015. Neste sentido, alerta Hoffmann (2012, p. 32) que "A criança não pode se sentir integrada a uma escola que the proporciona uma situação constante de prova, de teste, onde a tensão se mantém e onde ela e sua família são prejulgadas e responsabilizadas pelo fracasso".

Segundo Nogaro (2013), os professores envolvidos na aprendizagem das crianças são essenciais para que a criatividade e a expressão do pensamento sejam articuladas. Em outras palavras, a aprendizagem deve ser criativa e, por isso, a educação interdisciplinar deve ser trabalhada como princípio epistemológico e pedagógico, fazendo com que as crianças experimentem diferentes saberes e áreas do conhecimento.

No entanto, o que verificamos é que nas duas últimas décadas, a avaliação passou a ser, por excelência, o processo que indica ou não a qualidade do ensino, apontando a direção de educação que se pretende alcançar e, assim, se obstruem as vias para uma educação integral, reproduzindo um ensino para a competitividade, o individualismo e a fragmentação do saber. Uma das reflexões em questão, portanto, é o conceito hegemônico sobre qualidade de ensino e o indicador usado para medi-la.

Nas escolas pesquisadas do referente município, a proposta político-pedagógica possui uma visão metódica de avaliação por resultados e com intenção na obtenção de prêmios, tais como abono salarial tanto para os professores quanto para o núcleo gestor. Embora isso ocorra com menos frequência na Educação Infantil, acaba produzindo, desde cedo, nas crianças, a ideia da avaliação e da necessidade de um bom desempenho. Isso porque, de certa forma, as políticas educativas ficam subordinadas à lógica da economia neoliberal, "[...] a partir do momento que comparam sistemas e classificam escolas segundo seus desempenhos, com a finalidade de obter mais vantagem competitiva e atrair melhores alunos e professores" (BALL, 2005, p. 39). 
Esta concepção de avaliação, adotada pelo município, identifica-se com uma perspectiva “[...] de segmentação, de parcelarização do conhecimento" (HOFFMANN, 2011, p. 34), ou seja, é atribuído um conceito, grau ou nota, a uma criança/aluno, sem a devida interpretação ou questionamento quanto ao seu significado e poder. Além disso, "[...] impede que professores e alunos estabeleçam uma relação de interação a partir da reflexão conjunta, do questionamento, sobre hipóteses formuladas pelo educando em sua descoberta do mundo" (HOFFMANN, 2011, p. 17).

Entretanto, o Estágio Supervisionado nos cursos de graduação, especificamente no curso de Pedagogia da UVA, adota perspectiva contrária a esse processo avaliativo do município, pois, "[...] a proposta de avaliação deve exigir do professor uma concepção de criança como sujeito do seu próprio desenvolvimento, inseridos no contexto de sua realidade social e política" (HOFFMANNN, 2011, p. 18). Neste sentido, entendemos o estágio como a oportunidade de inovar as práticas educativas do exercício docente no contexto escolar.

É neste sentido, pois, que consideramos um desencontro entre a nossa praxis interdisciplinar e a política de resultados nas escolas pesquisadas. Dito de outra maneira, nossa praxis interdisciplinar no estágio da Educação Infantil surgiu há cerca de seis anos, quando iniciamos a nova matriz curricular do curso de Pedagogia da UVA. Nela, há dois componentes curriculares independentes, mas interligados: Estágio Supervisionado em Educação Infantil (80 h/a) e Práticas Interdisciplinares na Educação Infantil (20 h/a), sendo cada um de reponsabilidade de um/uma professor/a. Inicialmente, cada docente realizava separadamente sua prática pedagógica. Mas, em determinado momento, cada uma/um solicitou um projeto de estágio à turma, sobre o qual, imediatamente os/as acadêmicos/as solicitaram uma reflexão.

A partir deste momento, com a participação discente, as professoras-pesquisadoras atuantes nos dois componentes curriculares precisaram refletir sobre uma nova prática docente. Desde então, passaram a dialogar, planejar e acompanhar coletivamente a elaboração e aplicação do projeto interdisciplinar em Educação Infantil, assim como, o Relatório final.

Essa reorganização interna implicou em um redimensionamento externo. A realização do estágio nas escolas repercutiu positivamente, com mais coerência e consistência. Se anteriormente as escolas públicas municipais, imbuídas na política de resultados, focavam em conhecimentos matemáticos e linguísticos - portanto, de certa forma, pressionavam para que os Estágios Supervisionados se adaptassem a essa proposta - posteriormente, passaram a valorizar e permitir melhor essa atuação interdisciplinar.

Nesta pesquisa, vamos descrever e analisar os passos percorridos para compartilhar experiências exitosas no contexto do estágio, fortalecendo a relação teoria/prática na formação docente e na aproximação entre universidade e escola, uma vez que "[...] o ato de narrar experiências existenciais e profissionais permite transformar saberes implícitos em conhecimento (pesquisa) e ao mesmo tempo promover a reinvenção de si (formação)". (PASSEGGI, 2008, p. 240). Em outras palavras, abordar a reflexão sobre a prática docente é tornar o "[...] professor autor e ator, [...] sujeito de sua própria história". (PIMENTA; ANASTASIOU, 2002, p. 21). Neste sentido, a elaboração do projeto interdisciplinar e a aplicação no Estágio Supervisionado é o contexto de concretização para as mudanças na formação docente. 
Por fim, o objetivo desta pesquisa foi identificar e analisar as (in) congruências entre o curso de Pedagogia e as escolas municipais, no que diz respeito à práxis interdisciplinar no Estágio Supervisionado em Educação Infantil. O contexto da pesquisa foi o Curso de Pedagogia da Universidade Estadual Vale do Acaraú (UVA), Ceará, e nas escolas públicas de um município do mesmo estado. Estas, por sua vez, possuem uma proposta pedagógica que adota e enfatiza a avaliação externa no Infantil $\mathrm{V}$, bem como supervaloriza os eixos de Linguagens e Códigos, por meio de uma proposta político-pedagógica com uma perspectiva predominantemente destinada à obtenção de resultados quantitativos.

\section{O ESTÁGIO SUPERVISIONADO COMO PRÁXIS FORMATIVA INTERDISCIPLINAR NA DOCÊNCIA UNIVERSITÁRIA}

Refletir sobre o Estágio Supervisionado é questionar a formação docente em si, a configuração no espaço universitário e no seu contato com a realidade profissional nas escolas, uma vez que a exigência por qualificação profissional tem sido cada vez maior. Segundo Lima (2008) é por meio do estágio que se pode estabelecer uma conexão propícia para o diálogo e a reflexão sobre a cultura docente, cultura escolar e universitária para que se possa abstrair as aprendizagens delas decorrentes.

Deste modo, entende-se o estágio como componente essencial na formação docente porque é nele que decorre a aprendizagem da docência e, consecutivamente, neste momento formativo, os acadêmicos afloram ou confrontam a sua identidade profissional nas situações vividas (LIMA, 2008). Porém, para que o estágio tenha seu objetivo atingido, é preciso que este seja encarado com seriedade por todos os envolvidos, inclusive, pelos demais professores das disciplinas do curso, que, de forma direta ou indireta, contribuem com a caminhada do estagiário, podendo potencializar ou desvalorizar as atividades.

Pimenta e Lima (2017) defendem que o estágio nos cursos de formação de professores deve possibilitar aos acadêmicos compreender a complexidade das práticas institucionais e das ações praticadas pelos profissionais que ali atuam. Não obstante, isso somente será possível "se o estágio for uma preocupação, um eixo de todas as disciplinas do curso" (PIMENTA; LIMA, 2017, p. 35). Isso, porque, se todas as disciplinas tiverem essa preocupação com o estágio, incluindo-o em seu planejamento, fundamentando e refletindo sobre a prática vivenciada pelos acadêmicos, teremos como resultado uma ação pedagógica potencializada na formação docente, acadêmicos com maior reflexividade e pensamento crítico sobre a sua formação, prática docente e toda a cultura institucional que permeia o estágio.

Nesta perspectiva, a experiência aqui relatada sobre a integração entre Estágio Supervisionado e a disciplina de Práticas Interdisciplinares, mesmo sendo uma integração curricular parcial, já reflete positivamente na práxis formativa dos estagiários.

Desta forma, percebemos que na prática docente universitária há inúmeras experiências, sejam elas de caráter educativo ou pedagógico, que podem contribuir para a melhoria da formação de professores e o quão essas ações podem refletir no espaço social do cotidiano. Assim, se faz necessário entender a universidade como um campo de construção do conhecimento coletivo, onde os professores são elos entre o âmbito acadêmico e o profissional no contexto formativo, em que se deve ter a consciência de que este elo precisa ser 
fortalecido, não somente em refletir sobre tais questões, mas também “[...] por iniciativas de mudança, pela coragem da acção" (NÓVOA, 2017, p. 1115).

Segundo Nóvoa (2017), é preciso edificar uma nova configuração para a formação de professores, para que esta aproxime cada vez mais a universidade e escola; e, assim, criar projetos inovadores, novas metodologias na formação docente; para, dessa maneira, fortalecer o plano da formação, da identidade docente e do reconhecimento da profissão professoral.

Deste modo, precisa-se tomar consciência de que a profissão docente, no contexto da educação, se configura como uma das formas de intervir na realidade social, considerada, assim, uma "prática educativa" e, "portanto, uma prática social" (PIMENTA; ANASTASIOU, 2002, p. 178). Ou seja, são os professores universitários que, pensando e agindo sobre e na realidade, podem transformar as práticas que consequentemente poderão contribuir para o diálogo entre as diferentes instâncias educativas, reforçando o potencial da profissão e o espaço de formação dos futuros licenciados.

Enfim, é importante esclarecer que quando se fala de prática educativa, refere-se "[...] a práticas que ocorrem para a concretização de processos educacionais" (FRANCO, 2012, p.152). Pimenta e Anastasiou (2002, p. 179) complementam ainda que esta dita prática educativa deve ser entendida como "[...] um traço cultural compartilhado que tem relações com o que acontece com outros âmbitos da sociedade e de suas instituições. Portanto, pesquisar a prática impõe-se como caminho para a transformação delas". Assim, é preciso que, no fazer docente, faça-se uso da pesquisa, da teoria educativa e didática para que se possa interligar a prática ao todo, dando sentido e razões à esfera pedagógica.

\section{INTERDISCIPLINARIDADE}

Vivemos numa sociedade que se apresenta num mundo paradoxal, local de múltiplos saberes, de verdades relativas, de indeterminações, ambivalências e contradições, colocando para o homem contemporâneo o desafio de (sobre)viver, ainda que, para isso, este precise fragmentar-se para que não se perca de si mesmo. Neste sentido, exige-se uma mudança na construção de conhecimentos, por conta da complexidade da atual sociedade, que privilegia o comportamento e o pensamento interdisciplinar, como forma de se estar no mundo.

Por interdisciplinaridade, Lück (2010) define-a como:

\footnotetext{
o processo que envolve a integração e engajamento de educadores, num trabalho conjunto, de interação das disciplinas do currículo escolar entre si e com a realidade de modo a superar a fragmentação do ensino, objetivando a formação integral dos alunos, a fim de que possam exercer criticamente a cidadania, mediante uma visão global de mundo e serem capazes de enfrentar os problemas complexos, ambos e globais da realidade atual. (LÜCK, 2010, p. 72)
}

Por meados de 1960, iniciam no Brasil as primeiras discussões sobre interdisciplinaridade, por meio da qual buscavam mudar o processo de ensino aprendizagem, segundo a necessidade de uma nova forma de educar por meio da integração das disciplinas, fugindo da educação tradicional, que fragmenta os saberes e produz uma formação acrítica e conteudista. 
A interdisciplinaridade, todavia, não conseguiu, de imediato, conquistar espaço nas escolas brasileiras, pois propunha mudanças: uma nova postura de ensino aos educadores que, acomodados ao modelo tradicional de educação, resistiram por muito tempo às transformações que a prática interdisciplinar defende. Isso ocorria porque os professores se encontravam imersos a um currículo disciplinar monótono e a uma educação fragmentada, preocupada apenas em transmitir conteúdos específicos.

Neste sentido, Gallo (2001) analisa essa concepção curricular de ensino, alertando que

No currículo disciplinar tudo pode ser controlado: o que o aluno aprende, como aprende, com que velocidade o processo acontece e assim por diante. Tudo pode ser avaliado: o desempenho do aluno, a 'produtividade' do professor, a eficácia dos materiais didáticos etc. Dessa forma, todo o processo pode ser metrificado e o desempenho do aluno traduzido numa nota, às vezes com requintes de fragmentação, incorporados no número de casas decimais. (GALLO, 2001, p. 169)

Por outro lado, "[...] num currículo multidisciplinar os alunos recebem informações incompletas e têm uma visão fragmentada e deformada pelo mundo" (ANDRADE, 1998, p.97). Dito de outra maneira, no currículo interdisciplinar, os diversos conhecimentos compõem uma totalidade de significação, ou seja, se estabelece entre os saberes das disciplinas uma integração e uma relação com as vivências dos educandos.

A interdisciplinaridade é vista como um elemento de apoio dentro do processo educacional em todos os níveis escolares, inclusive na Educação Infantil. Porém, a prática interdisciplinar na Educação Infantil, precisa ser melhor explorada, pois o contexto histórico sobre o assunto revela que somente a partir dos anos de 1930, seguindo os ideais do bem-estar social e a aceleração do processo de urbanização, foi que as crianças começaram a estabelecer contato com instituições de ensino. Tal mudança foi possível porque as mulheres começaram a trabalhar nas fábricas e necessitavam deixar seus filhos em um lugar que cuidasse deles. Então, estes locais constituíram-se, aos poucos, nas primeiras escolas. Até então, as crianças ainda eram consideradas como mini-adultos, pois as atividades realizadas eram basicamente as mesmas de seus pais (ARIÈS, 1981).

A interdisciplinaridade, conceito que vem sendo estudado e debatido desde a década de 1960 no campo universitário, pode ser compreendida "[...] inicialmente, como tentativa de elucidação e classificação temática das propostas educacionais que começavam a aparecer na época" (FAZENDA, 1994, p. 18). Neste viés, vem se constituindo como um termo polissêmico, ao se tornar objeto de pesquisa de muitos teóricos na tentativa de fazer uma definição epistemológica, na busca de uma unidade conceitual. Assim, de maneira mais específica, é definida por Fazenda (2000) como "[...] uma nova atitude diante da questão do conhecimento, de abertura à compreensão de aspectos ocultos do ato de aprender e dos aparentemente expressos, colocando-os em questão. Exige, portanto, na prática uma profunda imersão no trabalho cotidiano" (FAZENDA, 2000, p. 7).

Deste modo, entende-se que o conceito interdisciplinar parte de uma integração entre as disciplinas, levando em consideração as ações ou situações do cotidiano, procurando contextualizar o conhecimento e fazendo com que cada disciplina, a seu modo, contribua para o desenvolvimento da temática elucidada. 
Porém, Fazenda (2008) alerta que a proposta interdisciplinar somente se torna possível onde várias disciplinas se reúnem sobre o mesmo objeto, ou seja, tenham um eixo norteador da prática, um objeto central que, na formação docente, poderíamos nomear de Estágio Supervisionado. Esse, por sua vez, é categorizado por Pimenta e Lima (2017), como objeto da práxis. Segundo elas, "o estágio curricular é atividade teórica de conhecimento, fundamentação, diálogo e intervenção da realidade" (PIMENTA; LIMA, 2017, p. 36). Neste sentido, essa combinação de ações acadêmico-pedagógicas na práxis seria dialogicamente coerente à interdisciplinaridade necessária para o cotidiano da prática educativa do estágio, estabelecendo então significativas reflexões.

Partindo deste princípio, Pombo (2005) equipara a universidade à escola, acrescentando àquela a importância que se deve dar à interdisciplinaridade:

Mas, se a universidade não é apenas uma escola, a verdade que ela também é
uma escola e, enquanto escola, ela tem que preparar para a interdisciplinari-
dade. Ela tem que perceber as transformações epistemológicas em curso e, de
alguma maneira, ir ao seu encontro. Ela tem que se preparar, não apenas para
não oferecer resistências ao trabalho interdepartamental mas para, além disso,
promover esse tipo de experiências, facilitar novos tipos de configurações dis-
ciplinares, aceitar fazer investigação sobre os novos problemas que se colocam
à ciência contemporânea (POMBO, 2005, p.12).

Para isso, a autora propõe:

Criar, se possível, circunstâncias e mecanismos que favoreçam a compreensão dos próprios fenômenos interdisciplinares que estão a ocorrer na ciência e na universidade. Por exemplo, 1) tornando viável a constituição e desenvolvimento dos novos campos interdisciplinares de investigação e ensino que o progresso do conhecimento científico requer; 2) promovendo o desenvolvimento de atitudes, hábitos e formas de trabalho interdisciplinares; 3) fomentando a prática de um ensino que promova uma integração dos saberes cada vez mais profunda; 4)apoiando a constituição de programas de investigação e de ensino em História das Ciências, em Epistemologia, em Filosofia das Ciências (POMBO, 2005, p. 12).

Logo, essa relação interdepartamental e intersetorial da universidade com a escola precisa ser dinâmica, orgânica e fluída. Sentimos a necessidade de estimular esta relação no nosso contexto de pesquisa, na relação entre Estágio Supervisionado, na proposta pedagógica do município e na gestão das escolas.

\section{AValiação eXterna No INFANTIL V}

Neste item, vamos expor a proposta político-pedagógica do município onde ocorreu a pesquisa sobre avaliação externa nas turmas do Infantil V, assim como suas contradições com a práxis interdisciplinar do Estágio Supervisionado do curso de Pedagogia.

Para isso, identificamos avaliação externa como aquelas aplicadas em larga escala, a nível nacional, regional e municipal, através de provas para mensurar quantitativamente o conhecimento das crianças. 
Nos últimos anos, nas escolas públicas, a avaliação passou a ser, por excelência, o processo que indica ou não a qualidade do ensino, apontando a direção da educação que se pretende alcançar. (OLIVEIRA, 2014). Segundo o Ministério da Educação do Brasil (MEC), a Prova Brasil e o Sistema Nacional de Avaliação da Educação Básica (SAEB) são avaliações para diagnóstico, em larga escala, com o objetivo de avaliar a qualidade do ensino oferecido pelo sistema educacional brasileiro a partir de testes padronizados e questionários socioeconômicos (BRASIL, 2018).

As metas propostas por estes documentos, acima mencionados, são avaliadas pelo Programa Internacional de Avaliação dos Estudantes (PISA), uma iniciativa internacional de avaliação comparada. No Brasil, ele é coordenado pelo Instituto Nacional de Estudos e Pesquisas Educacionais Anísio Teixeira (INEP).

Os programas nacionais e internacionais que norteiam as políticas públicas educacionais visam à obtenção de notas através de metas e, sendo assim, a avaliação em larga escala na educação básica ganhou grande centralidade - do controle de resultados à intervenção nos processos de operacionalização do ensino no Brasil nos últimos anos. Um dos entraves aparentes a ser questionado e que se encontra em evidência no nosso sistema escolar é justamente este indicador na qualidade do ensino e da aprendizagem: a avaliação.

Nos últimos tempos, nas escolas de Educação Infantil, tem ocorrido a exclusão da cultura da infância, pois desde cedo as crianças já entram em contato com conteúdos encontrados mais comumente nos anos escolares do Ensino Fundamental e que são inerentes às hierarquias disciplinares contempladas nas avaliações externas. Nestas práticas, há dois equívocos enormes: o primeiro deles se refere à antecipação das práticas escolares próprias do Ensino Fundamental, visibilizadas por rotinas rígidas, horários esquadrinhados entre aulas de diferentes tipos, pouco tempo de atividades ao ar livre e de autônoma escolha das crianças e $\square$ como não mencionar? $\square$ a adoção de apostilas/cartilhas por muitas escolas/ redes particulares e públicas.

O segundo equívoco refere-se à antecipação das práticas avaliativas próprias (mas também questionáveis) do ensino como um todo, que é a aplicação de provas de conteúdos de alfabetização em língua materna e matemática; a aplicação de instrumentos de controle de comportamentos das crianças como por exemplo, tirar o recreio porque não fez a tarefa no prazo determinado; a organização das crianças em mesas por desempenho; o excesso de tarefas para casa com o intuito de preparar as crianças para a realidade do Ensino Fundamental, e outras mais que certamente abundam Brasil adentro.

Pensando nisso, Tomazzetti et al. (2019), sintetiza em palavras a realidade cotidiana das práticas político-pedagógicas na escola da educação básica:

Muitas vezes, pressionados pela organização burocrática da escola, professoras e professores são obrigados a apresentar um plano de trabalho envolvendo, de forma detalhada, os $\square$ conteúdos $\square$ a serem apresentados às crianças ao longo da semana ou do mês. Estes se tornam, por um lado, elementos de controle do trabalho docente e, por outro, limitadores da experiência das crianças, pois neles, em geral, não cabe a curiosidade emergente, o imprevisto, a vida pulsante de um grupo de crianças. (TOMAZZETTI et al., 2019, p. 381). 
Este investimento no preparo das crianças ao longo dos últimos anos da Educação Infantil tem também o intuito de elas obterem bons resultados nas avaliações e, assim, antecipam uma prática de premiação por bons resultados na Educação Infantil por sua contribuição ao sistema como um todo!. As escolas de Educação Infantil são, por estes meios, reconhecidas como entes de um mesmo sistema. Enquanto isso, o tempo das crianças para brincar, interagir com o mundo, explorar e se divertir na Educação Infantil é utilizado pelas instituições para efetivarem o treinamento mecanizado e cansativo dos conteúdos ofertados a elas.

Essa ação adotada pelas escolas de educação infantil só reitera o fato de que parte da essência da infância das crianças é perdida quando elas adentram no espaço escolar, pois seus saberes trazidos dos vários espaços onde elas circulam não são valorizados pelo trabalho pedagógico. Ou seja, na maioria das vezes as crianças não são sequer conhecidas em suas necessidades e especificidades, menos ainda, ouvidas na escola. Neste viés, os alunos são $\square$ Mergulhados acriticamente numa sociedade competitiva, familiares e profissionais de educação apoiam a adoção de práticas escolares que abreviam a infância, acreditando ser possível e adequado que as crianças aprendam conteúdos escolares cada vez mais cedo $\square$ (TOMAZZETTI, et al., 2019, p. 376).

Assim, perpetua-se e se acredita que, quanto mais cedo as crianças tiverem contato com os conteúdos escolares, mais cedo elas aprenderão. O que não é verdade, pois grande parte das crianças não consegue se adequar à rotina repetitiva e exaustiva que o ensino desses conteúdos exige, abreviando dessa forma, a infância delas e prejudicando sua formação social e pessoal. Como vemos, uma decorrência desta perspectiva é que o trabalho pedagógico que envolve a Educação Infantil está atrelado a um controle por meio das instituições de ensino, pois as proposições devem estar alinhadas aos conteúdos que as crianças precisam aprender durante o ano letivo, objetivando que logrem êxito nas avaliações externas a que são submetidas.

Esses aspectos pedagógicos na Educação Infantil condicionam as crianças a terem contato somente com assuntos de cunho escolar-formativo. Contudo, a cultura infantil, que deveria ser a base das práticas educativas na e trabalhada também na escola, é rejeitada e esquecida.

Como complemento do diálogo aqui estabelecido, apresenta-se um trecho de uma entrevista realizada na pesquisa com a coordenadora da Educação Infantil da Secretaria Municipal de Educação, onde está situado o Centro de Educação Infantil pesquisado. Nosso foco, como pesquisadoras, estava voltado para a avaliação externa que o município realiza com as crianças da Educação Infantil ao longo do ano. Queríamos entender o que é essa avaliação e como ela acontece. De acordo com a Coordenadora da Educação Infantil do município:

Do infantil bebê até o infantil IV, ela acontece de forma bimestral por relatórios, relatório descritivo da criança e individual. Nada impede que já na pré-escola, no infantil $\mathrm{IV}$, as escolas e os CEIS já iniciem um processo de acompanhamento da aprendizagem da criança. E aí algumas escolas e os CEIS, eles utilizam vários instrumentos para medir ou acompanhar esse tipo da aprendizagem. (Entrevista com a coordenadora da educação infantil - Diário de campo - 12 de dezembro de 2019). 
Posteriormente, foi perguntado à coordenadora da Educação Infantil se existia algum documento que falasse sobre essa avaliação nesta área, ao que ela informou não haver nenhum documento elaborado, mesmo existindo orientações para acompanhamento pela Superintendência Pedagógica da SME:

Acredito que nós não temos nenhum documento elaborado, né, pra gente fazer. Quem acompanha é a casa da avaliação, a superintendência pedagógica. Essa avaliação na Educação Infantil ela é feita de forma muito.... É... não tem nada muito burocratizado nela, nem mesmo em documentos, porque o intuito dela é apenas pra gente ver como é que a criança tá saindo do infantil, ela não tem nem outro tipo de objetivo, ou de fiscalização ou avaliação em si desempenho, de aprendizagem. Então, ela é feita de forma muito leve. Pra escola isso talvez não seja tão leve, porque de qualquer forma é uma avaliação. E qualquer que seja a avaliação, se você chegar aqui e dizer: coordenadora, eu venho lhe avaliar, eu vou já me preparar e ficar... né? Então, qualquer avaliação ela não é um processo tranquilo. E aí, nós não temos!. (Entrevista com a coordenadora da educação infantil - Diário de campo - 12 de dezembro de 2019)

\section{Após essa fala da coordenadora, ela foi questionada acerca do conteúdo da avaliação. Obtivemos como resposta:}

Nós não tínhamos um currículo para a Educação Infantil, então, foi pego lá no início, acho que em 2005, um material didático que era utilizado na época, da aprender editora, da Daniele Macambira, não sei se você conhece. E foram olhados esse material, e vendo que a criança poderia aprender, ao final da modalidade da educação infantil, ela deveria sair sabendo, pelo material didático, e então foi selecionado uma matriz de referência, que ela foi ao longo dos anos, ela foi sendo aperfeiçoada. (Entrevista com a coordenadora da educação infantil $\square$ Diário de campo - 12 de dezembro de 2019).

Na sequência, perguntamos à coordenadora se essa matriz funcionava como um caderno de indicação, ao que ela respondeu, corrigindo:

De indicadores! São indicadores, indicadores da linguagem oral, indicadores da matemática, aí dentro desses blocos, está a lateralidade, cores, textura, né! Grande, pequeno, longe, perto, embaixo, em cima, que faz parte da lateralidade, alfabeto, leitura de palavras, é... escritas de contextos, posso depois até lhe encaminhar a matriz de referência, não tem nenhum tipo de problema. E aí, a ideia que nós temos pra agora é que hoje nós temos um currículo, e esse currículo foi todo apoiado na Base Nacional Comum Curricular, e aí base nacional comum já nos aponta alguns objetivos de aprendizagens e habilidades, e essa estão lá contidas no nosso currículo, e apenas no infantil IV e V há um acréscimo de alguns indicadores que vieram do currículo do ensino fundamental. O currículo do ensino fundamental, ele já tem os indicadores de aprendizagem do $1^{\circ}$ ano. Entendendo que não faz sentido a gente esperar que a criança entre no $1^{\circ}$ ano com um perfil que tá cobrando lá no $1^{\circ}$ ano e que na educação infantil a gente não garanta esse perfil. E aí, os professores deverão trabalhar de forma lúdica, através de vivências e experiências, aquela atividade. Então, assim, a avaliação é um pouco isso, pra educação infantil. (Entrevista com a coordenadora da educação infantil - Diário de campo - 12 de dezembro de 2019). 
Diante da ausência de documentos oficiais sobre a avaliação na educação infantil e da nova documentação (currículo) da SME, nos apoiamos na entrevista dessa Coordenadora da Educação Infantil no município pesquisado e passamos a proceder com os passos metodológicos que explicitam os conflitos entre a proposta pedagógica na Educação Infantil das escolas e a proposta interdisciplinar lúdica do Estágio Supervisionado do curso de Pedagogia da UVA.

\section{Procedimento metodológico}

A pesquisa se caracteriza como pesquisa qualitativa. A escolha da abordagem se justifica pela perspectiva de atuar com o universo de significados, aspirações e valores que não podem ser quantificáveis (MINAYO, 2001).

Esta pesquisa se iniciou como atividade didático-pedagógica do curso de Pedagogia na Universidade Estadual Vale do Acaraú (UVA) e envolveu todas as alunas matriculadas nas turmas do sétimo e do oitavo períodos. O critério de escolha foi o fato de elas terem realizado o estágio em Educação Infantil no sexto período. Nossa intenção foi avaliar a experiência de estágio entre a universidade e as escolas públicas. O questionário aplicado procurou compreender quais as principais dificuldades enfrentadas durante o estágio na Educação Infantil. A totalidade de alunas envolveu 43 universitárias, sendo 21 acadêmicas do sétimo e 22 acadêmicas do oitavo período. Para que a pesquisa pudesse ser divulgada, todas as alunas, assim como a coordenadora da secretaria de educação do município e as gestoras escolares, leram e assinaram o Termo de Consentimento Livre Esclarecido - TCLE.

Pimenta e Lima (2004) destacam que, durante o estágio, há uma dicotomia frequente entre a teoria e a prática, pois a maioria dos estagiários acredita que a parte teórica vista nas disciplinas das universidades, tornam-se nulas quando se veem no campo prático. No nosso caso, o curso de Pedagogia da UVA, por não possuir uma escola de formação, possui um componente curricular de Práticas Interdisciplinares. A aplicação deste no estágio, todavia, precisa, na maioria das vezes, entrar em conflito com a proposta político-pedagógica das escolas públicas do município, que possuem maior foco nos estudos da área de Linguagens e Códigos.

Neste viés, Lima (2012) defende que o estágio é de suma importância, pois promove a inserção dos futuros professores na escola, já que os estagiários aprendem - por meio dos erros, acertos e desafios - a resolver as dificuldades diárias que aparecem na escola. Portanto, ao longo dos anos, percebemos que há uma barreira epistemológica entre a proposta do curso de Pedagogia da UVA e a proposta político-pedagógica do município onde ocorreu a pesquisa.

Além do mais, o sexto período do curso de Pedagogia tem como eixo central a Educação Infantil. Este eixo é composto por vários componentes curriculares: disciplinas, seminários e oficinas. Por esse motivo, desde que a matriz curricular foi inaugurada, ministra-se o Seminário de Práticas Interdisciplinares na Educação Infantil. Inicialmente, as 20 horas-aula eram ministradas com apresentação da coordenadora da Educação Infantil da Secretaria de Educação do município e de outras escolas particulares. Cada uma apresentava, em um turno diário, a perspectiva teórico-metodológica de sua instituição e ilustrava com os projetos interdisciplinares. 
Nas primeiras experiências na disciplina, portanto, ficou claro a ênfase curricular em Linguagens e Códigos dada pela Secretaria de Educação do município onde foi realizada a pesquisa. Assim como foi possível identificar a predominância da abordagem socioconstrutivista das escolas particulares. Além do mais, não havia diálogo com a professora do Estágio Supervisionado na Educação Infantil, do curso e, consequentemente, não havia articulação entre os dois componentes curriculares. Por esses motivos, os/as acadêmicos(as) elaboravam dois projetos no mesmo semestre. Entretanto, depois de um tempo de conversas e entendimentos, as duas professoras entraram em um acordo e reelaboraram um único projeto, contemplando os dois componentes curriculares. Isto trouxe mais entendimento e maior vigor à proposta.

\section{Resultados dA PESQUisa}

Iniciaremos a análise dos dados com uma tabela que sintetiza as respostas obtidas nos questionários, tanto com as(os) acadêmicas(os) do sétimo, quanto com as(os) acadêmicas(os) do oitavo períodos. Para compreendermos melhor os resultados da pesquisa, a tabela 1, abaixo, exemplifica de maneira simples como se organizou a escolha das respostas das universitárias do sétimo e oitavo período. É possível observar também quais dificuldades as universitárias de cada período enfrentaram com mais frequência.

Tabela 1: Respostas das Universitárias do Sétimo e Oitavo Período

\begin{tabular}{l|c|c|c}
\hline $\begin{array}{l}\text { Quais as principais dificuldades enfrentadas durante } \\
\text { o estágio na educação infantil? }\end{array}$ & $\begin{array}{c}7^{\circ} \\
\text { Período }\end{array}$ & $\begin{array}{c}8^{\circ} \\
\text { Período }\end{array}$ & \\
\hline A escola demorou a responder sua solicitação de estágio & 02 & - & 4.6 \\
A escola não aceitou o seu estágio & 01 & - & 2.3 \\
A escola não aceitou o estágio de 5 turnos - 20 horas & 02 & 08 & 23.2 \\
A escola exigiu a mudança do projeto interdisciplinar & - & 01 & 2.3 \\
Ausência de um supervisor na escola & 11 & 06 & 39.5 \\
Não houve dificuldade & 01 & 01 & 4.6 \\
Elaboração do projeto pedagógico interdisciplinar & 04 & 06 & 23.2 \\
\hline TOTAL & $(21)$ & $(22)$ & $(100)$ \\
\hline
\end{tabular}

Fonte: Tabela elaborada pelas pesquisadoras

\section{Relatos das universitárias do oitavo semestre}

Neste tópico, destacamos as respostas das(os) acadêmicas(os) do oitavo período, que apontaram questões referentes às perguntas feitas no questionário. As universitárias serão identificadas por números.

A experiência de integração entre o Seminário de Práticas Interdisciplinares na Educação Infantil e Disciplina de Estágio em Educação Infantil foi avaliada como "muito importante, pois é através do estágio que podemos observar a sala, para depois elaborar um projeto adequado" (U.12), pois "contribui de forma significativa, facilitando a aplicação e 
construção do projeto" e porque "é uma articulação da teoria e da prática" (U.16), afirmaram as universitárias 12 e 16, respectivamente.

Outros relatos relevantes para a pesquisa encontram-se nas palavras da universitária 09: "[... ] foi muito proveitosa a oportunidade de conhecer o conceito de interdisciplinaridade, de pensar em atividades interdisciplinares, indispensável na educação infantil” (U. 09), pois "é muito produtivo criar um projeto baseado nas necessidades das crianças" (U.03). Para a universitária 16, “[...] os dois componentes curriculares estão em harmonia, além disso, a escola aderiu ao projeto". (U. 16).

Para outras 06 universitárias, a elaboração do projeto pedagógico interdisciplinar foi difícil diante da novidade da proposta que rompe com a disciplinaridade. Segundo os relatos: "[...] existiam dificuldades para planejar atividades que envolvessem e atraíssem as crianças e que abordassem realmente a interdisciplinaridade" (U. 12). Segundo as alunas e os alunos do curso, é porque os professores "[...] ainda encontrassem-se submersos na metodologia tradicional de ensino" (U. 04). As dificuldades para a elaboração do projeto justificaram-se porque, para a maioria dos alunos do curso de Pedagogia, esta é a primeira experiência com o planejamento de um projeto interdisciplinar e o tempo com o professor orientador da disciplina resumem-se em apenas 20 horas/aula.

Dentre as (os) 22 universitárias (os) pesquisadas pertencentes ao grupo do oitavo período, 08 universitárias afirmaram que a maior dificuldade para aplicação do projeto interdisciplinar no estágio concentrava-se no fato da escola não ter aceitado o estágio de 5 turnos (20 horas-aula). De acordo com a universitária 18, “A escola achava que isso atrapalhava a concentração dos alunos” (U. 18). Tal afirmação é reforçada pela universitária 09, quando diz que "A escola colocou empecilhos cortando pela metade o tempo do plano elaborado, ou seja, de 20 horas-aula ficaram 10 horas-aula" (U.09), dificultando "Colocar em prática todas as atividades elaboradas no projeto" (U. 03).

Tais relatos revelam que a escola não aceitado o estágio de 20 horas-aula fez com que a execução do projeto em sala de aula fosse prejudicada; ou seja, os resultados obtidos pelas universitárias não seriam alcançados em detrimento da diminuição do tempo.

Durante a coleta dos dados, identificaram-se 06 universitárias que apontaram como dificuldade a ausência de um supervisor na escola de estágio. Apenas 01 universitária afirmou que a escola exigiu a mudança na estrutura do projeto interdisciplinar e 01 outra aluna disse não ter tido dificuldades.

\section{Relatos das universitárias do sétimo período}

Entendemos que a pesquisa não conseguiria prever, na entrevista, todas as possíveis dificuldades e causas resultantes destas. Por isso, foi solicitado às (os) 21 universitárias (os) pesquisadas (os) que apresentassem outros itens não contemplados no questionário. De acordo com o relato da universitária 07 , um item não contemplado no questionário foi que:

[...] o semestre chegava ao fim na escola e as avaliações externas eram o foco. Todos os dias uma sala iria ter que fazer uma prova na modalidade de Linguagens ou Códigos. Não havia tempo para que eu pudesse aplicar o projeto interdisciplinar, foi preciso reduzir o tempo de aplicação para apenas 3 dias. (U.07). 
Do mesmo modo, as avaliações externas dificultaram a realização daquilo que foi planejado para o estágio. Neste sentido, a universitária 02 ressalta:

[...] não consegui aplicar o projeto da forma que deveria ter sido, as crianças da educação infantil estavam sendo avaliadas e como a avaliação é oral, pediram que fizéssemos atividades que as crianças não fizessem barulho para não atrapalhar, porém foi um pouco difícil segurar o entusiasmo dos alunos frente as atividades que envolviam todos os eixos além de arte e movimento. (U.02).

Ainda sobre o fato das avaliações, a universitária 04 enfatiza:

[...] quando fui aplicar o projeto, fiquei assustada, a escola estava em festa, existiam vários cartazes espalhados com frases afirmando que os alunos eram capazes de vencer, gravuras referentes às notas e crianças sorridentes, até a merenda da escola foi diferente no dia da avaliação, e por causa disso não pude aplicar o projeto nesse dia. (U.04).

Como observamos nos relatos acima, nos períodos de avaliação externa nas escolas, estas ficam quase totalmente voltadas aos objetivos inerentes a estes eventos, dificultando qualquer outra atividade. Na Educação Infantil, as avaliações de Códigos (Matemática) concentram-se em saber se os alunos conhecem as cores; se têm noções de distância, tamanho, peso; e se conseguem diferenciar as formas geométricas. Além disso, as crianças também são testadas quanto à escrita dos números em sequência de 0 à 30 . Em Linguagem (Português), as perguntas são direcionadas ao reconhecimento das letras do alfabeto e sua escrita; ao reconhecimento da primeira letra dos nomes das crianças; à sequência lógica de uma história; e à leitura de palavras básicas, como: gato, boneca, bola, casa.

Dentre os desafios apontados durante a pesquisa, encontramos relatos que reforçam outras dificuldades existentes, mas que ainda passam despercebidas, tais como "a falta de infraestrutura fisica da escola" (U. 05). No município onde ocorreu a pesquisa, é comum as escolas se utilizarem de prédios anexados a um prédio principal para o funcionamento de aulas para os alunos da Educação Infantil. No entanto, a estrutura física desses anexos é, em sua maioria, pequena e sem adaptações necessárias em banheiros para crianças ou sem espaços adequados para a brincadeira livre e atividades psicomotoras.

\section{Conclusão}

Portanto, verificamos que existem vários desafios da formação de professores da educação infantil na UVA, pois a perspectiva interdisciplinar assumida pelo curso de Pedagogia contrasta e vai de encontro à política de resultados quantitativos das escolas municipais da região onde se realizou a pesquisa.

No entanto, essas dificuldades ocorrem também no âmbito universitário, durante a elaboração do projeto interdisciplinar, devido à pequena carga horária de 20 horas-aula; à mudança de paradigma da proposta disciplinar para a proposta interdisciplinar; à ausência de um supervisor escolar; à burocratização dos documentos de estágio; à redução do número de acadêmicos nas turmas de estágio; à integração de todas as disciplinas do eixo; e, por fim, à dificuldade no diálogo com as secretarias de educação e seus representantes. 
Portanto, os resultados apontam como incongruências: infraestrutura precária em algumas escolas; a dificuldade inicial na aceitação dos estagiários pelos gestores e professores; a aplicação das provas externas no mesmo período do estágio nas turmas do Infantil V; a exigência de mudança na estrutura e nos temas dos projetos para adequar-se aos eixos de Linguagens e Códigos, entre outros. Destacando-se, porém, como a principal dificuldade encontrada, a compreensão epistemológica sobre a práxis interdisciplinar, no contexto escolar.

Não obstante, reconhecemos como congruências: a criação de um espaço de diálogo com as professoras e gestoras escolares; aceitação e fortalecimento das práticas lúdicas; a superação da fragmentação de conhecimentos, de forma a contribuir significativamente na formação das (os) pedagogas (os), aliando teoria e prática.

Neste embate, ao longo dos anos, temos conseguido modificar/influenciar, minimamente, a proposta da secretaria de educação do município onde se deu a pesquisa, principalmente através do Estágio Supervisionado. Além disso, somam-se às estratégias supracitadas: a elaboração e divulgação de trabalhos de conclusão de curso, monitorias e participação em eventos acadêmico-científicos. Embora existam muitas dificuldades, algumas escolas já começaram a adotar algumas práticas interdisciplinares, denominadas sequências didáticas. Tudo isso incide, portanto, em um avanço no processo de valorização da formação docente e da primeira infância.

\section{REFERÊNCIAS}

ARIÈS, P. História Social da criança e da família. Tra- dução de Dora Flaksman. 2a ed. Rio de Janeiro, Zahar, 1981.

ANDRADE, R. C. Interdisciplinaridade: um novo paradigma curricular. In: GOULART, Iris Barbosa (Org.). A educação na perspectiva construtivista: reflexões de uma equipe interdisciplinar. 2. ed. RJ:Vozes, 1998.

BALL, S. J. Profissionalismo, Gerencialismo e Performatividade. Cadernos de Pesquisa, 35(126), 539-564, 2005.

BALL, S. J. Performatividades e fabricações na economia educacional: rumo a uma sociedade performativa. Educação \& Realidade. 35(2), 37-55, 2010.

BRASIL. Ministério da Educação. Diretrizes curriculares nacionais para a educação infantil. Brasília, 2010. Disponível em: http://portal.mec.gov.br/index.php?option=com docman $\&$ view $=$ download $\&$ alias $=9769$-diretrizescurriculares-2012\&category_slug=janeiro-2012-pdf\&Itemid=30192 Acesso em: 10 Fev. 2019.

BRASIL. Ministério da Educação. RCNEI - Referencial Curricular Nacional da Educação Infantil. V.1.Brasília: MEC, 1998. Disponível em: http://portal.mec.gov.br/seb/arquivos/pdf/rcnei_vol1.pdf Acesso em: 18 Fev. 2019. 
FAZENDA, I.C. A. Interdisciplinaridade: história, teoria e pesquisa. 15. ed. Campinas, São Paulo: Papirus, 1994.

FAZENDA, I. C. A. Integração como proposta de uma nova ordem na Educação. In: FAZENDA, I. C. A. Linguagens, espaços e tempos. Rio de Janeiro: Agir, 2000.

FAZENDA, I. C. A. Interdisciplinaridade- transdisciplinaridade: visões culturais e epistemológicas. In: FAZENDA, I. C. A. (org.) O que é Interdisciplinaridade?. São Paulo: Cortez, 2008.

FRANCO, M. A. R. S. Pedagogia e prática docente. 1. ed. São Paulo: Cortez, 2012.

GALLO, S. Disciplinaridade e transversalidade. 2. ed. ENDIPE. In: Linguagens, espaços e tempos no ensinar e aprender. Rio de Janeiro: DPEA, 2001.

HOFFMANN, J. Avaliação: mito e desafio: uma perspectiva construtiva. Porto Alegre: Mediação, 2011.

HOFFMAN, J. Avaliação e educação infantil: Um olhar sensivel e reflexivo sobre a criança. Porto Alegre: Mediação, 2012.

LIMA, M. S. L. Produção de conhecimento sobre estágio supervisionado. In: LIMA, M.S.L. Estágio e aprendizagem da profissão docente. Brasília: Liber livro, 2012.p. 123-135.

LIMA, M. S. L. Reflexões sobre o estágio/Prática de ensino na formação de professores. Rev. Diálogo Educ., Curitiba, 2008, v. 8, n. 23, p. 195-205, jan./ abr. 2008.

LÜCK, H. Gestão Educacional: uma questão paradigmática. Série cadernos de gestão. $5^{\circ}$ edição, Petrópoles, RJ: Editora Vozes, 2010.

MINAYO, M. C. S. Ciência, técnica e arte: O desafio da pesquisa social. In: MINAYO, M. C. S. (org). Pesquisa social, teoria, método e criatividade. 18. ed. Petrópolis: Vozes, 2001, p. 9-31.

NOGARO, A.Diálogos com Reggio Emilia:escutar, investigar e aprender. Revista Perspectiva. v. 37 , n. 140 , dezembro, 2013.

NÓVOA, A. Firmar a profissão como professor, afirmar a profissão docente. In: Cadernos de Pesquisa. V.47, N. 166, p. 1106-1133, out./dez., 2017.

OLIVEIRA, D. D. A interdisciplinaridade no processo de ensino-aprendizagem nas turmas do quinto ano: entre o real e o ideal. Trabalho de Conclusão de Curso. Universidade Estadual Vale do Acaraú. Curso de Pedagogia. Sobral - CE, 2014. 
PADIAL, K. avaliação na educação infantil. Avaliação na Educação Infantil - O olhar sobre as crianças. Disponível em: gestaoescolar.org.br. Acesso em 09 mar. 2021.

PASSEGGI, M. da C. Mediação biográfica: figuras antropológicas do narrador e do formador. In: PASSEGGI, M. da C.; BARBOSA, T. M. N. (Org.). Memórias, memoriais: pesquisa e formação docente. Natal: EDUFRN; São Paulo: Paulus, 2008, p. 43-59.

PIMENTA, S. G.; ANASTASIOU, L. G. C. Docência no Ensino Superior. V.1. São Paulo: Cortez, 2002.

PIMENTA, S. G.; LIMA, M. S. L. Estágio e docência. 8. ed. Ver. Atual. E ampl. São Paulo: Cortez, 2017.

PIMENTA, S.G; LIMA, M.S.L. Estágio e docência. São Paulo: Cortez, 2004.

POMBO, O. Interdisciplinaridade e integração dos saberes. In: Liinc em Revista, v.1, n.1, março 2005 , p. 3 -15.

SABÓIA, R. B. V.; ASTIGARRAGA, A. A. A prática educativa no estágio supervisionado: uma perspectiva interdisciplinar. In: ADAD, Shara jane Holanda Costa; LIMA, Joana Dárc de Sousa; BRITO, Antonia Edna (Orgs.). Práticas educativas: Múltiplas experiências em educação. Fortaleza-Ceará, EDUECE, 2021.

TOMAZZETTI, Cleonice; SANTOS, Maria Walburga; MELLO, Suely Amaral. Questões candentes na educação infantil: porque as crianças ainda são crianças. In: SANTOS, Maria Walburga; TOMAZZETTI, Cleonice Maria; MELLO, Suely Amaral (Orgs.). Eu ainda sou criança: educação infantil e resistência. São Carlos: EDUFSCAR, 2019, 398 p.

\section{DAdos das aUtoras}

\section{Andrea Abreu Astigarraga}

Doutora em Educação pela Universidade Federal do Ceará (UFC), Pós-Doutorado pela Universidade Federal do Rio Grande do Norte (UFRN). Docente associada na Universidade Estadual Vale do Acaraú (UVA). astigarragaandrea@yahoo.com

\section{Railane Bento Vieira Sabóía}

Graduada em Pedagogia pela Universidade Estadual Vale do Acaraú (UEVA). Mestranda em Educação Pela Universidade Estadual do Ceará (UECE).railanebento@gmail.com

Submetido em: 01-11-2020

Aceito em: 31-03-2021 